\title{
"Medical Matrix" : A Directory of Clinical, Medical Web Sites
}

Vicky Duncan, BA, MLS, Health Sciences Library University of Saskatchewan, Saskatchewan, Canada

\section{REPRINT REQUESTS:}

Vicky Duncan, B.A., M.L.S.

Information Services Librarian

Health Sciences Library

University of Saskatchewan

107 Wiggins Road, Saskatoon

Saskatchewan S7N 5E5

Telephone: 306-966-6023

Fax: 306-966-5918

Email:vicky.duncan@usask.ca

\section{KEYWORDS:}

Internet; Medical informatics; Information storage and retrieval

RECEIVED:

September 9, 2002

REVISED AND ACCEPTED:

September 12, 2002

Clinical Medicine \& Research

Volume 1, Number 1: 71 - 72

(C2003 Clinical Medicine \& Research

www.mfldclin.edu/clinmedres

\section{REVIEW OF MEDICAL MATRIX}

\section{INTRODUCTION}

Physicians and health care workers today face a 'googleplex' of medical Internet resources claiming to assist them in making clinical decisions. Unfortunately, one can spend an inordinate amount of time trying to sift the 'wheat from the chaff, especially if one uses a search engine such as Google. While Google is an excellent search engine, there is no human being behind the scenes screening the sites for quality and usefulness.

\section{DIRECTORIES VS. SEARCH ENGINES}

Far more useful for the busy healthcare worker is a 'directory' of resources or web sites. A 'directory' is a hand-selected listing of web sites, which have been reviewed, and recommended by an editorial or review board.

One of the best examples of this type of directory is 'Medical Matrix,' available at http://www.medmatrix.org/info/about.asp. Created by Dr. Gary Malet, the intended audience is primarily American physicians and healthcare workers who prescribe treatment for disease conditions.

Medical Matrix is "devoted to posting, annotating, and continuously updating full content, unrestricted access, Internet clinical medicine resources." A secondary goal is to include sites that "can be utilized during the time span of a patient visit." For the most part, this reviewer believes that Medical Matrix succeeds admirably in achieving its goals.

\section{EDITORIAL BOARD}

The success of Medical Matrix is due to the well-qualified editorial board, comprised of academics and practicing specialists. As members of the American Medical Informatics Association's Internet Working Group, they also have a special interest in the online dissemination of information. Interesting to note is that three medical librarians are listed as contributors to the project. Evidence of their expertise is apparent in the site's organization and classification 


\section{ORGANIZATION}

The organization of Medical Matrix is based on eight main sections:

Specialties

Diseases

Clinical Practice

Literature

Education

Healthcare and Professionals

Medical Computing, Internet and Technology

Marketplace

Standardization of each section provides the user with access to relatively quick and painless browsing. For example, in the 'Specialties' section, sites are always listed under the following headings:

Searches; News; Full Text / MultiMedia; Journals;

Textbooks; Major Sites / Home Pages; Procedures;

Practice Guidelines; FAQs; Cases; Images,

Path./Clinical; Images, X-Ray; CME; CE; Patient

Education; Directories; Educational Materials;

Classifieds; and Forums.

The majority of the web sites appear in the first section, 'Specialties'. More than 50 'Specialties' are listed alphabetically followed by the number of web sites included in that specialty, for example, "Emergency Medicine (120)". When the user selects any of the 'Specialties', a list of rated and annotated web sites is displayed.

\section{RATINGS}

Web sites are reviewed and rated according to the following criteria:

Dimension/usefulness for clinical application (1-10 pts)

Peer Review, Authority, Hierarchies of Knowledge (1-10 pts)

Verifiability, clarity, and integrity (1-10 pts)

Evidence-based criteria (1-10 pts)

Media (1-5 pts)

Feel/ease of access (1-5 pts)

Each web site is given a star rating by the reviewer. The highest rating is five stars which is "an award winning site for Medical Internet," and has received 41-50 points.

The lowest rating that a site can receive and still qualify for inclusion is one star. One star sites are awarded between 1 and 10 points by a reviewer, and are defined as "suitable, well-authored clinical content but lacking in substance, or currency."

Although the criteria focus is clearly and appropriately on reviewed, authoritative and evidence-based resources, a web site has to receive only 1-10 points to qualify for one star, and therefore inclusion on Medical Matrix. Using these criteria, a web site could quality if it just used multimedia in interesting ways.

\section{CONTENT}

The annotation for each web site provides an insight to the site's content, and assists in the "to click or not to click" decision. Although the annotations are useful, a more critical and thorough description would benefit the user. Knowing the weaknesses of the sites would further sort "wheat from chaff." For example, a description that provides knowledge as to why a site received three stars, as opposed to five - is it not updated regularly or is it not peer reviewed?

Inclusion of the date the site was last visited by the reviewer would also be helpful in the dynamic world of the Internet.

It is also worth noting, that despite the claim to provide access to sites that are "unrestricted," many of the sites included do require either registration and/or payment. These sites are clearly labelled though, with either a "\$" (paid subscription required) or the word "REG" (registration required) following the star rating.

\section{SEARCH OPTIONS}

"Medical Matrix" is well-designed for the user to browse through sites on a given topic. It is also possible, to "search" the site using the Medical Matrix search engine. Important to keep in mind, though, is that the search engine does not search of the entire Medical Matrix directory, but rather the contents of selected web sites.

The search engine browses the 1.5 million documents that have been selected by a team of physicians and medical librarians. Searches have consistently returned high-quality, clinically relevant results. Unfortunately this feature is now available only with a paid subscription.

\section{PRICE}

Until recently, Medical Matrix has been available free of charge. Effective September 1, 2002, access is available only by subscription. Individuals may subscribe for $\$ 79 /$ per year, and multi-use subscribers, including medical libraries, for $\$ 199 /$ per year.

Is the cost warranted? Yes. There are a small handful of directories that provide annotations and ratings. This reviewer has located few other Internet directories that select, rate, annotate and organize clinical medical web sites as successfully as Medical Matrix does.

\section{CONCLUSION}

This reviewer has been pleased with the selection of sites and has regularly recommended it to many practicing clinicians over the last five years.

Medical Matrix is highly recommended. 